
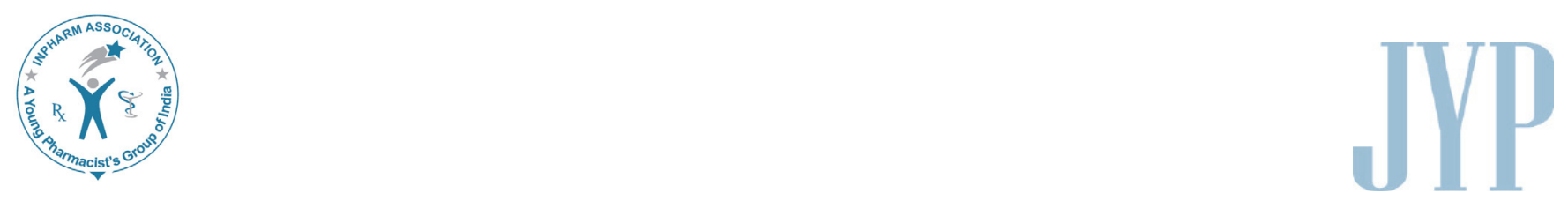

\title{
Microbial Contamination of Tooth Brushes Stored in Different Settings before and After Disinfection with Chlorhexidine-A Comparative Study
}

\author{
Jagadeeshwar Rao Sukhabogii ${ }^{*}$, Byalakere Rudraiah Chandrashekar², Nova \\ Haritha ${ }^{1}$, Gujjarlapudi Satish Kumar', Irrukula Venkata Ramana ${ }^{3}$, Lingam \\ Jaya Lakshmi ${ }^{4}$, Sanka Pavani ${ }^{4}$ and Durga Vasundara ${ }^{1}$ \\ ${ }^{1}$ Department of Public Health Dentistry, Govt Dental College and Hospital, Hyderabad, Telangana State, India. \\ ${ }^{2}$ Department of Public Health Dentistry, JSS Dental College and Hospital, JSS University, Mysore, India. \\ ${ }^{3}$ Department of Orthodontia, Govt Dental College and Hospital, Hyderabad,Telangana State, India. \\ ${ }^{4}$ Department of Microbiology, Osmania Medical College and Hospital,Hyderabad, Telangana State, India.
}

\begin{abstract}
Objective: To qualitatively and quantitatively assess the microbial contamination of tooth brushes preserved in different sanitary settings before and after disinfection with $0.2 \%$ chlorhexidine. Materials and Method: The study was carried out in two phases among thirty participants visiting a dental hospital. These participants were assigned to one of the three groups based on the practice of preserving the tooth brush. Group 1: Participant's who preserved their brush outside the bathroom. Group 2: Participant's who preserved their brush within the bathroom without attached toilets. Group 3: Participants who preserved their brush within the bathroom with attached toilets. Participants were given oral hygiene kits containing a brush and paste in the first phase. The brush samples were collected on day thirty for qualitative and quantitative estimation of microbial contamination. In the second phase, participants were requested to rinse their brushes in $0.2 \%$ chlorhexidine after brushing and before placing it back. The mean CFU of different bacteria was compared using independent sample t-test and paired sample t-test. Results: The tooth brushes stored outside the bathrooms demonstrated the presence of Candida, Streptococci, Klebsiella, Staphylococcus aureus and Lactobacillus. Pseudomonas, Candida, Streptococci, Staphylococcus aureus and Lactobacillus was demonstrable in the tooth brush samples of group 2. Pseudomonas, Candida, Streptococci, Klebsiella, Staphylococcus aureus, Lactobacillus, Proteus and E.coli were all demonstrable in group 3. However, the disinfection with $0.2 \%$ chlorhexidine reduced the microbial load substantially. Conclusion: Rinsing the tooth brush with $0.2 \%$ chlorhexidine substantially reduced the microbial contamination in all the three settings.
\end{abstract}

Key words: Chlorhexidine, Lactobacillus, Microbial contamination, Streptococcus mutans, Tooth brush.

\begin{tabular}{|c|c|}
\hline \multicolumn{2}{|c|}{ Access this article online } \\
\hline Journal Sponsor & \multirow[b]{2}{*}{$\begin{array}{l}\text { Website: } \\
\text { www.jyoungpharm.org }\end{array}$} \\
\hline \multirow{2}{*}{ www.phcog net } & \\
\hline & $\begin{array}{l}\text { DOI: } \\
\text { 10.5530/jyp.2015.4s.11 }\end{array}$ \\
\hline
\end{tabular}

\section{INTRODUCTION}

Tooth brushes are a vital component of routine oral hygiene aids used in promotion of oral health and prevention of oral diseases. ${ }^{1}$ Unfortunately, they are often stored in unsanitary conditions such as bathrooms.

\footnotetext{
*Address for correspondence:

Dr. Jagadeeshwar Rao Sukhabogii, Assistant Professor, Department of Public Health Dentistry, Govt Dental College and Hospital, Hyderabad, Telangana State, India.E-mail:drjrsukhabogi@gmail.com
} 


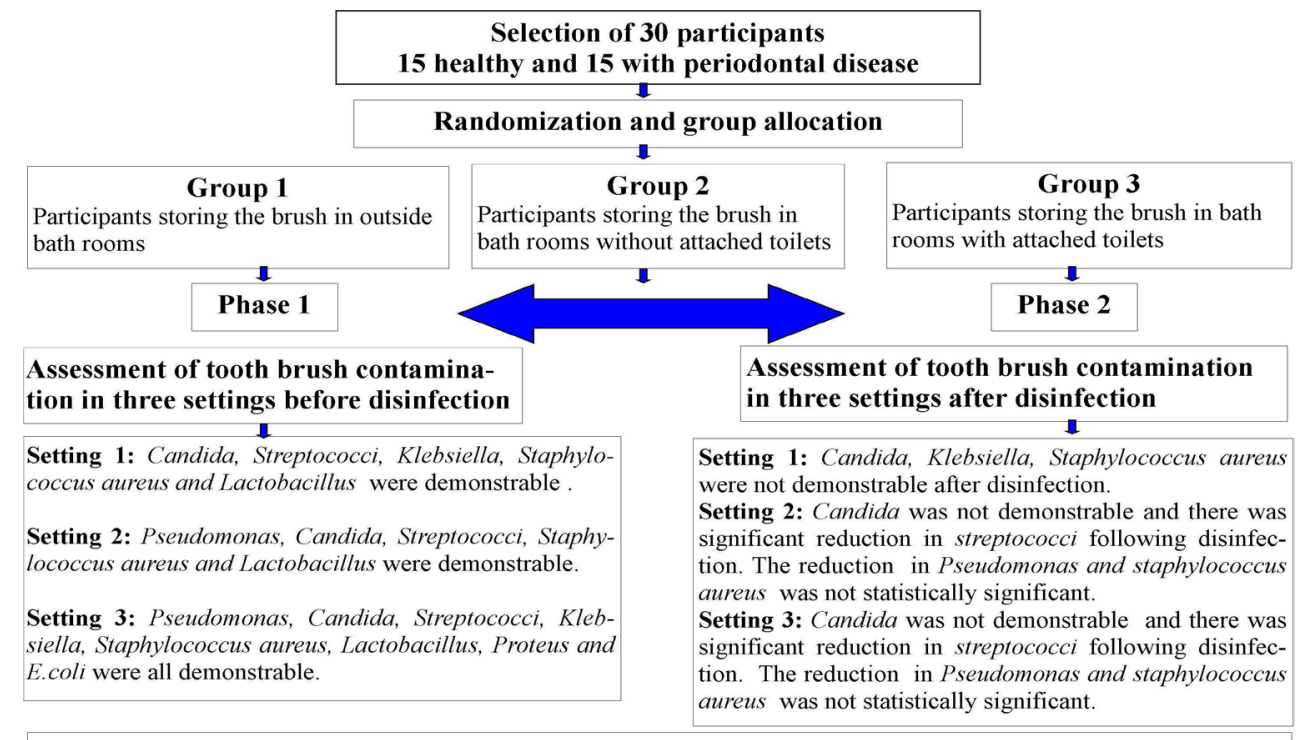

Conclusion: Rinsing the tooth brush with $0.2 \%$ chlorhexidine substantially reduced the microbial contamination in all the three settings.

\section{Graphical Abstract}

These unsanitary conditions are the settings that harbor millions of different pathogenic microbes. The neglect in the appropriate maintenance of tooth brushes is attributed to lack of public awareness on the possibilities of tooth brush contamination while they are stored after brushing. ${ }^{2}$ The colonization of pathogenic micro-organisms on toothbrush while being stored in unsanitary conditions represents a potential cause of re-contamination of the oral cavity. ${ }^{3}$ The tooth brush may get contaminated by Streptococcus, Staphylococcus and Lactobacilli. ${ }^{4,5}$ These bacteria are implicated in the causation of many life threatening diseases such as infective endocarditis besides influencing the occurrence of oral diseases such as dental caries and gingivitis.,

The effectiveness in removing dental plaque of a manual tooth brush lasting approximately three months or more may reduce owing to the flaring of tooth brush bristles. ${ }^{7}$ Hence, American Dental Association (ADA) recommends change of tooth brush every 3-4 months. The average life span of a manual toothbrush is approximately 3 months. ${ }^{8}$ However, microbial contamination was not given any attention while recommending the frequency for change of toothbrush. The studies demonstrating the contamination of toothbrushes preserved in sanitary settings before and after simple disinfection process are sparse. In this background, the present study was undertaken to qualitatively and quantitatively assess the microbial contamination of tooth brushes preserved in different sanitary settings before and after disinfection with $0.2 \%$ chlorhexidine.

\section{MATERIALS AND METHODS}

This comparative study was carried out among thirty participants visiting the department of Public Health Dentistry, Government Dental College, Hyderabad after the ethical clearance was obtained from the Institutional Ethics Committee vide letter number GDCH/ETHC/4/2015. At the preliminary visit, a clinical oral examination was carried out by a dentist to assess their oral health status besides collecting desired information on other systemic diseases. The list of participants free from systemic diseases who visited the department between $1^{\text {st }}$ and $10^{\text {th }}$ September 2014 was prepared. These participants were recalled for a health education program organized by the department in the third week of September 2014. The participants were educated on benefits of good oral hygiene for optimal oral and general health by a Public Health Dentist. All the participants were given an oral hygiene kit containing 100 gram tooth paste and a soft bristled brush following the completion of health education session. Modified Bass Technique was demonstrated to the participants and they were directed to brush twice daily. The information on where the participants preserved their brush after brushing was recorded at this time. Based on this information, the participants were assigned to one of the three categories.

Group 1: Participant's who preserved their brush outside the bathroom

Group 2: Participant's who preserved their brush within the bathroom without attached toilets 
Group 3: Participants who preserved their brush within the bathroom with attached toilets.

Ten participants were recruited in each group and within each group; five were healthy while the others were with mild to moderate periodontitis. Then, these participants were informed that their brush will be collected at the end of one month for a microbiological assay and their consent obtained. The participants were requested not use any antimicrobial mouth rinses during the study period. Each of these participants was given a sterile transparent zip lock plastic pouch. They were requested to place their brush in the zip lock pouch after using their brush in the morning on day thirty.

\section{Sample collection}

At the end of one month, samples were collected from each participant. On the intended day for sample collection, the participants were instructed to rinse the brush in tap water after brushing and place it in the zip lock pouch. Five investigators collected these samples from the participant's households and sent them for laboratory investigations on the same day. At the time of sample collection, the information on how and where the brush was preserved during the last thirty days, use of any antibiotics during the study period was obtained. This information helped in making exclusions. The individuals using any antibiotics during the study period and deviating from the assigned practice of preserving the brush were excluded.

\section{Sample collection following disinfection}

In the second phase of the study, each participant was given a oral hygiene kit containing tooth brush, tooth paste and a disinfecting solution (100 $\mathrm{ml}$ of $0.2 \%$ chlorhexidine). The participants were directed to use the tooth brush and preserve it in the routine setting. However, they were directed to immerse their brush in $5 \mathrm{ml}$ of the disinfecting solution for 20 seconds before placing the brush back in the location intended for its preservation. Antimicrobial solution was distributed at ten days interval. This ensured that the participants were reinforced about the disinfection of their tooth brush and facilitated compliance on the recommendation given to them. The brushes were collected on day thirty and sent for microbial assay.

\section{Isolation of organisms}

Handles of toothbrushes were cut off using heat sterile scissors. Heads of the brushes (containing the bristles) were then soaked in $10 \mathrm{ml}$ of sterile tryptone soya broth (TSB) for 60 minutes. This was followed by vortex mixing for 1 min to dislodge suspected adherent bacteria. The bacterial suspension was serially diluted to obtain dilution factors of up to $10^{3}$. The spread plate technique was employed. One milliliter $(1 \mathrm{ml})$ each of the dilution factors was obtained using a sterile pipette and plated on agar plate. MacConkey agar and Mannitol salt agar media were used for the isolation of non-fastidious bacteria, coliforms and staphylococci, respectively. Plates were incubated aerobically at $37^{\circ} \mathrm{C}$ for $24-48 \mathrm{~h}$.

\section{Identification of isolates}

Total viable counts of bacterial population were enumerated. Morphological characteristics of isolates were observed and Gram's staining was performed for each isolate.

- Gram positive cocci of Manitol salt agar were further identified as Staphylococcus aureus and Staphylococcus epidermidis by several biochemical tests such as Catalase test, Oxidase test, Coagulase test, Carbohydrates fermentation test and others.

- Gram negative bacilli on MacConkey plates were identified as follows: a. Gram negative, non lactose fermenting, oxidase positive colonies were considered as Psendomonas species b. Gram negative, lactose fermenting, oxidase negative colonies were considered as Coliform species.

\section{Statistical analysis}

The data was entered on to a personal computer and statistical analysis was carried out using SPSS version 20. The mean CFU of bacteria between the healthy and periodontitis subjects in each of these groups was compared using independent sample t-test while the mean CFU of bacteria before and after disinfection in each group was compared using paired sample t-test. The statistical significance was fixed at 0.05 . The CONSORT flow diagram is depicted as Figure 1.

\section{RESULTS}

Thirty participants aged between 19 to 45 years, with a mean of $28.9 \pm 7.9$ years participated in the study with no exclusions made from the baseline. The age distribution of healthy and diseased individuals in each of the three groups is denoted in Table 1.

The tooth brushes stored outside the bathrooms demonstrated the presence of Candida, Streptococci, Klebsiella, Staphylococcus aureus and Lactobacillus. These microorganisms were demonstrable in the tooth brushes of healthy as well as diseased individuals. The mean bacterial load of 


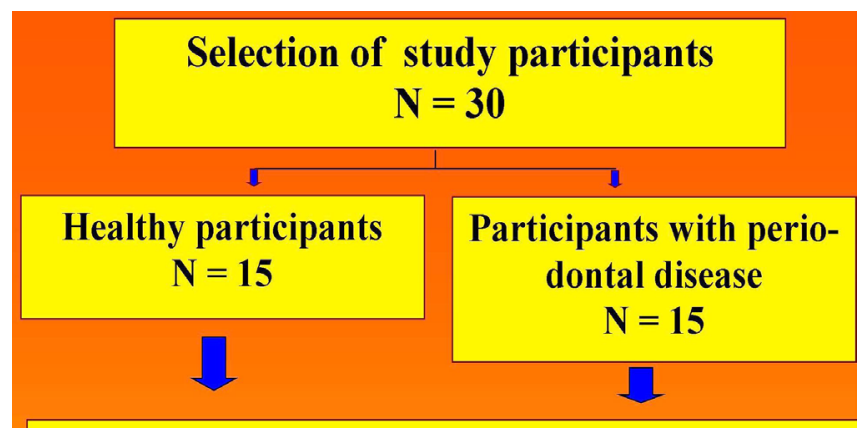

Group allocation and distribution of tooth brushes

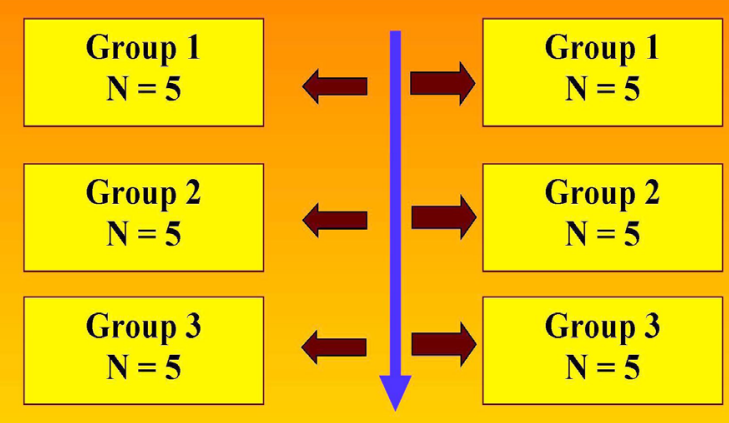

Assessment of microbial contamination in tooth brush samples before disinfection

\begin{tabular}{c}
$\begin{array}{c}\text { Distribution of tooth brushes for second phase } \\
\text { along with disinfectant rinse }\end{array}$ \\
\hline
\end{tabular}

\section{Assessment of microbial contamination in tooth} brush samples after disinfection

\section{Data analysis}

Figure 1: Consort Flow Diagram Dipicting Methodology in the Present Study
Table 1: Age distribution of study participants in different groups

\begin{tabular}{|c|c|c|c|}
\hline Group & Health status & $\begin{array}{l}\text { Number of } \\
\text { participants }\end{array}$ & Mean Age \\
\hline \multirow{2}{*}{ Group 1} & Healthy & 5 & $23.4 \pm 0.6$ \\
\hline & Diseased & 5 & $32.0 \pm 4.4$ \\
\hline \multirow{2}{*}{ Group 2} & Healthy & 5 & $21.4 \pm 1.5$ \\
\hline & Diseased & 5 & $39.6 \pm 3.6$ \\
\hline \multirow{2}{*}{ Group 3} & Healthy & 5 & $21.8 \pm 1.9$ \\
\hline & Diseased & 5 & $35.4 \pm 5.9$ \\
\hline \multicolumn{2}{|c|}{ Total } & 30 & $28.9 \pm 7.9$ \\
\hline
\end{tabular}

Candida (Table 2, $\mathrm{p}=0.017$ ) and Staphylococcus aureus (Table $2, \mathrm{p}=0.001)$ was significantly higher in the tooth brush samples collected from diseased individuals compared their healthy counterparts. The samples collected from group 1 participants failed to demonstrate the presence of Pseudomonas, Proteus and E.coli.

However, following disinfection with $0.2 \%$ chlorhexidine in the second phase of the study, Candida, Klebsiella, Staphylococcus aureus which were demonstrable in the first phase were not demonstrable. The mean CFU of streptococcus were significantly lower among tooth brush samples collected both healthy (Table 2, $\mathrm{p}=0.01$,) and diseased individuals (Table $2, \mathrm{p}=0.01$ ) compared to the results of the first phase where no disinfection was followed before preserving the brush in the intended location. Although, the mean CFU of lactobacillus was reduced compared to baseline levels, the reduction observed was not statistically significant in both the subgroups.

Pseudomonas, Candida, Streptococci, Staphylococcus aureus and Lactobacillus were demonstrable in the tooth brush samples collected from group two participants who stored their brush in bathrooms without attached toilets. These bacteria

Table 2: Microbial contamination of tooth brushes stored outside the bathroom (group 1) before and after using disinfectant

\begin{tabular}{|c|c|c|c|c|c|c|c|c|c|}
\hline \multirow[t]{2}{*}{ Intervention } & $\begin{array}{l}\text { Health } \\
\text { status }\end{array}$ & Pseudo & Candida & Strepto & KlebsI & Staphy & Lactobac & Proteus & E.coli \\
\hline & & \multicolumn{8}{|c|}{ Mean Colony Forming Units $/ \mathrm{ml} \pm$ Standard deviation } \\
\hline \multirow{2}{*}{ Before } & Healthy & NS & $\begin{array}{c}0.4 \pm 0.1 \\
\times 10\end{array}$ & $\begin{array}{c}1.8 \pm 0.4 \\
\times 10^{6}\end{array}$ & $\begin{array}{c}4.0 \pm 0.2 X \\
10^{2}\end{array}$ & $\begin{array}{c}5.4 \pm 1.4 \\
\times 10^{2}\end{array}$ & $\begin{array}{c}1.8 \pm 0.4 X \\
10^{2}\end{array}$ & NS & NS \\
\hline & Diseased & NS & $\begin{array}{c}1.0 \pm 0.4 \\
\times 10\end{array}$ & $\begin{array}{c}1.8 \pm 0.4 X \\
10^{6}\end{array}$ & $\begin{array}{c}27.6 \pm 0.8 X \\
10^{2}\end{array}$ & $\begin{array}{c}36.8 \pm 2.2 X \\
10^{2}\end{array}$ & $\begin{array}{c}1.8 \pm 0.4 \mathrm{X} \\
10^{2}\end{array}$ & NS & NS \\
\hline \multicolumn{2}{|c|}{ Statistical inference } & $\begin{array}{c}t=-3.0 \\
d f=8 \\
p=0.017\end{array}$ & $\begin{array}{c}t=0 \\
d f=8 \\
p=1.000\end{array}$ & $\begin{array}{c}t=-62.8 \\
d f=8 \\
p=1.000\end{array}$ & $\begin{array}{c}t=-26.6 \\
d f=8 \\
p=0.001\end{array}$ & $\begin{array}{c}t=0 \\
d f=8 \\
p=1.000\end{array}$ & & & \\
\hline \multirow{2}{*}{ After } & Healthy & NS & NS & $\begin{array}{c}1.2 \pm 0.2 \mathrm{X} \\
10^{6}\end{array}$ & NS & NS & $\begin{array}{c}1.1 \pm 0.6 \mathrm{X} \\
10^{2}\end{array}$ & NS & NS \\
\hline & Diseased & NS & NS & $\begin{array}{c}1.2 \pm 0.2 \mathrm{X} \\
10^{6}\end{array}$ & NS & NS & $\begin{array}{c}1.1 \pm 0.6 \mathrm{X} \\
10^{2}\end{array}$ & NS & NS \\
\hline \multicolumn{2}{|c|}{ Statistical inference } & & & $\begin{array}{c}t=0 \\
d f=8 \\
p=1.000\end{array}$ & & & $\begin{array}{c}t=0 \\
d f=8 \\
p=1.000\end{array}$ & & \\
\hline
\end{tabular}


Table 3: Microbial contamination of tooth brushes stored inside the bathroom without attached toilets (group 2) before and after using disinfectant

\begin{tabular}{|c|c|c|c|c|c|c|c|c|c|}
\hline Intervention & $\begin{array}{l}\text { Health } \\
\text { status }\end{array}$ & Pseudo & Candida & Strepto & Klebsl & Staphy & Lactobac & Proteus & E.coli \\
\hline \multirow[b]{2}{*}{ Before } & Healthy & $\begin{array}{c}4.8 \pm 1.4 \\
\times 10^{2}\end{array}$ & $\begin{array}{c}0.4 \pm 0.2 \\
\times 10\end{array}$ & $\begin{array}{c}1.8 \pm 0.3 X \\
10^{6}\end{array}$ & NS & $\begin{array}{c}5.4 \pm 1.4 \\
\times 10^{2}\end{array}$ & $\begin{array}{c}1.8 \pm 0.4 \\
\times 10^{2}\end{array}$ & NS & NS \\
\hline & Diseased & $\begin{array}{c}15.5 \pm 1.3 \mathrm{X} \\
10^{2}\end{array}$ & $\begin{array}{c}1.0 \pm 0.4 \\
\times 10\end{array}$ & $\begin{array}{c}1.8 \pm 0.4 X \\
10^{6}\end{array}$ & NS & $\begin{array}{c}36.8 \pm 2.2 \\
\times 10^{2}\end{array}$ & $\begin{array}{c}1.8 \pm 0.4 \\
\times 10^{2}\end{array}$ & NS & NS \\
\hline \multirow{3}{*}{\multicolumn{2}{|c|}{ Statistical inference }} & $t=-12.7$ & $t=-3.0$ & $t=0.0$ & & $t=-26.6$ & $t=0.0$ & & \\
\hline & & $d f=8$ & $d f=8$ & $d f=8$ & & $d f=8$ & $d f=8$ & & \\
\hline & & $p=0.001$ & $p=0.017$ & $p=1.000$ & & $p=0.001$ & $p=1.000$ & & \\
\hline \multirow{4}{*}{ After } & \multirow{2}{*}{ Healthy } & $3.9 \pm 0.7 X$ & \multirow{2}{*}{ NS } & $1.2 \pm 0.2 X$ & \multirow{2}{*}{ NS } & $4.0 \pm 0.2$ & $1.1 \pm 0.6$ & \multirow{2}{*}{ NS } & \multirow{2}{*}{ NS } \\
\hline & & $10^{2}$ & & $10^{6}$ & & $\mathrm{X} 10^{2}$ & $\mathrm{X} 10^{2}$ & & \\
\hline & \multirow{2}{*}{ Diseased } & $11.6 \pm 1.2 X$ & \multirow{2}{*}{ NS } & $1.2 \pm 0.2 X$ & \multirow{2}{*}{ NS } & $27.6 \pm 0.8$ & $1.1 \pm 0.6$ & \multirow[t]{2}{*}{ NS } & \multirow[t]{2}{*}{ NS } \\
\hline & & $10^{2}$ & & $10^{6}$ & & $X 10^{2}$ & $X 10^{2}$ & & \\
\hline \multirow{3}{*}{\multicolumn{2}{|c|}{ Statistical inference }} & $t=-12.5$ & & $t=-0.0$ & & $t=-62.8$ & $t=-0.0$ & & \\
\hline & & $d f=8$ & & $d f=8$ & & $d f=8$ & $d f=8$ & & \\
\hline & & $p=0.001$ & & $p=1.000$ & & $p=0.001$ & $p=1.000$ & & \\
\hline
\end{tabular}

\begin{tabular}{|c|c|c|c|c|c|c|c|c|c|}
\hline Intervention & $\begin{array}{l}\text { Health } \\
\text { status }\end{array}$ & Pseudo & Candida & Strepto & Klebsl & Staphy & Lactobac & Proteus & E.coli \\
\hline \multirow{4}{*}{ Before } & \multirow{2}{*}{ Healthy } & $4.8 \pm 1.4 X$ & $0.4 \pm 0.2$ & $1.8 \pm 0.4 X$ & $1.6 \pm 0.5$ & $5.4 \pm 1.4$ & $1.8 \pm 0.4$ & $1.4 \pm 0.6$ & $1.2 \pm 0.2$ \\
\hline & & $10^{2}$ & $X^{10}$ & $10^{6}$ & $\mathrm{X} 10^{2}$ & $\mathrm{X} 10^{2}$ & $\mathrm{X} 10^{2}$ & $\mathrm{X} 10^{2}$ & $\mathrm{X} 10^{2}$ \\
\hline & \multirow{2}{*}{ Diseased } & $15.5 \pm 1.3 X$ & $1.0 \pm 0.4$ & $1.8 \pm 0.4 X$ & $1.6 \pm 0.5$ & $36.8 \pm 2.2$ & $1.8 \pm 0.4$ & $1.4 \pm 0.6$ & $1.2 \pm 0.2$ \\
\hline & & $10^{2}$ & $\mathrm{X} 10$ & $10^{6}$ & $\mathrm{X} 10^{2}$ & $\mathrm{X} 10^{2}$ & $X 10^{2}$ & $\mathrm{X} 10^{2}$ & $\mathrm{X} 10^{2}$ \\
\hline \multirow{3}{*}{\multicolumn{2}{|c|}{ Statistical inference }} & $t=-12.7$ & $t=-3.0$ & $\mathrm{t}=0.0$ & $\mathrm{t}=0.0$ & $t=-26.6$ & $t=0.0$ & $t=0.0$ & $t=0.0$ \\
\hline & & $d f=8$ & $\mathrm{df}=8$ & $d f=8$ & $d f=8$ & $\mathrm{df}=8$ & $d f=8$ & $d f=8$ & $d f=8$ \\
\hline & & $p=0.001$ & $p=0.017$ & $p=1.000$ & $p=1.000$ & $p=0.001$ & $p=1.000$ & $p=1.000$ & $\mathrm{p}=1.000$ \\
\hline \multirow{4}{*}{ After } & \multirow[t]{2}{*}{ Healthy } & $3.9 \pm 0.7 X$ & \multirow[t]{2}{*}{ NS } & $1.2 \pm 0.2 X$ & \multirow[t]{2}{*}{ NS } & $4.0 \pm 0.2$ & $1.1 \pm 0.6$ & \multirow[t]{2}{*}{ NS } & \multirow[t]{2}{*}{ NS } \\
\hline & & $10^{2}$ & & $10^{6}$ & & $\mathrm{X} 10^{2}$ & $\mathrm{X} 10^{2}$ & & \\
\hline & \multirow{2}{*}{ Diseased } & $11.6 \pm 1.2 X$ & \multirow{2}{*}{ NS } & $1.2 \pm 0.2 X$ & \multirow{2}{*}{ NS } & $27.6 \pm 0.8$ & $1.1 \pm 0.6$ & NS & \multirow[t]{2}{*}{ NS } \\
\hline & & $10^{2}$ & & $10^{6}$ & & $\mathrm{X} 10^{2}$ & $\mathrm{X} 10^{2}$ & & \\
\hline \multirow{3}{*}{\multicolumn{2}{|c|}{ Statistical inference }} & $t=-12.5$ & & $t=-0.0$ & & $t=-62.8$ & $t=-0.0$ & & \\
\hline & & $d f=8$ & & $d f=8$ & & $d f=8$ & $d f=8$ & & \\
\hline & & $p=0.001$ & & $p=1.000$ & & $p=0.001$ & $p=1.000$ & & \\
\hline
\end{tabular}

were demonstrable in samples of both healthy and diseased participants in the group. However, the mean colony forming units (CFU) of Pseudomonas (Table 3, $\mathrm{p}=0.001$ ), Candida (Table 3, $\mathrm{p}=0.017$ ) and Staphylococcus aureus (Table 3, $\mathrm{p}=0.001)$ was significantly higher in the samples of diseased individuals compared to healthy individuals.

Following disinfection, Candida was not demonstrable in the samples collected from both healthy and diseased participants in this group. There was a significant reduction in the mean CFU of Streptococcus in the samples collected from both healthy (Table 3, $\mathrm{p}=0.004$ ) and diseased individuals (Table 3, $\mathrm{p}=0.012$ ) in this group compared to their baseline levels. Although, there was a reduction in the mean CFU of Pseudomonas and staphylococcus aureus following disinfection, the reduction was significant among the samples collected from diseased individuals (Table 3, $\mathrm{p}=0.001)$. The reduction in the mean CFU of Lactobacillus was not statistically significant in both the subgroups.

Pseudomonas, Candida, Streptococci, Klebsiella, Staphylococcus aureus, Lactobacillus, Proteus and E.coli were all demonstrable in the tooth brush samples collected from both healthy and diseased participants in group three who preserved their brush in bathrooms with attached toilets. The mean CFU of Pseudomonas (Table 4, $\mathrm{p}=0.001$ ) and Candida (Table 4, $\mathrm{p}=0.017)$ were significantly higher in tooth brush samples of diseased individuals compared to healthy participants in the group.

Candida was not demonstrable in the tooth brush samples collected following disinfection in both the subgroups. There was a significant reduction in the mean CFU of Streptococcus in both subgroups following disinfection 
(Table 4, $\mathrm{p}=0.01$ ). Although, there was a reduction in the mean CFU of Pseudomonas and staphylococcus aureus following disinfection, the reduction was significant among the samples collected from diseased individuals (Table 4, $\mathrm{p}=0.001)$. The reduction in the mean CFU of Klebsiella, Lactobacillus, Proteus and E.coli following disinfection was not statistically significant in both the subgroups.

\section{DISCUSSION}

The results of the present study established that the location at which tooth brushes are stored after brushing can act as a potential source of bacterial contamination highlighting the importance of adequate care. The appropriate methods of preservation of tooth brushes following oral hygiene practice needs to be stressed upon. The contaminated tooth brush could transmit infection among immunosuppressed, cardiopathic, organ transplant recipients. ' Candida, Streptococcus pyogens, Klebsiella, Staphylococcus aureus and Lactobacillus was found in the tooth brush samples preserved outside bathrooms. Pseudomonas, Candida, Streptococci, Staphylococcus aureus and Lactobacillus was demonstrable in the tooth brush samples preserved in bathrooms without attached toilets similar to the findings of other studies. ${ }^{2,3}$ Pseudomonas, Candida, Streptococcus pyogens, Klebsiella, Staphylococcus aureus, Lactobacillus, Proteus and E.coli was demonstrable in the tooth brush samples preserved in bathrooms with attached toilets similar to the findings of a study by Sumasogi HP et al (2002). ${ }^{9}$ The micro-organisms isolated from the tooth brush samples in our study are potential risk factors in the etiology of many general and oral diseases. Streptococcus and Lactobacillus, found in samples of tooth brushes collected from all the three settings are principle microorganisms involved in the causation of dental caries in human beings. ${ }^{10-12}$ Candida causes candidiasis. ${ }^{13}$ Pseudomonas can cause suppurative otitis, eye infections, urinary tract infections, burn infections, etc. ${ }^{2}$ Klebsiella causes pyogenic infections, septicemia, pneumonia, diarrhea, urinary tract infections. Streptococcus pyogenes causes urinary tract infections, rheumatic fever, glomerulonephritis. ${ }^{2}$ Staphylococcus causes boils, carbuncle, pustules, abscess, osteomyelitis, endocarditis and septicemia. ${ }^{14}$ E.coli is seen only in gut (enteric flora), but can get transmitted through aerosol contamination. Hence present only in brushes stored in bathrooms with attached toilets. E.coli is not influenced by the oral condition of the person but related only to storage place. Proteus is seen only in enteric flora, and aerosol contamination is a possible explanation in the samples of tooth brushes preserved in bathrooms with attached toilets. $^{2}$
The bacteria isolated in the present study not only are oral pathogens but also general pathogens. Inappropriate storage of toothbrushes in the bathrooms with or without attached toilet, exposing them to the unfavorable surrounding external environment may be a source of contamination by general pathogens. ${ }^{15}$ Oral commensals could also have contributed for contamination of toothbrushes. Toothbrushes contaminated with the microorganisms such as Pseudomonas, Sta. aureus and Klebseilla pose a serious threat to oral and general health.

The simple practice of immersing the tooth brushes in a disinfectant solution for 20 seconds can bring about a substantial reduction in the mean CFU of Streptococci besides completely eliminating Candida. Although, the reduction in the mean CFU of all other bacteria was not statistically significant, the small reduction noted was encouraging. These results were in agreement with the results of other studies. ${ }^{9,16}$

\section{Limitations}

The smaller sample size in the present study could be an explanation for not observing the reduction in the mean CFU as significant. In this context, our study could be considered as a pilot study and further studies with larger sample are recommended to validate the present results.

The use of anti-microbial solutions, air drying and toothbrush sanitizer are some of the recent methods available for preserving tooth brushes. Besides commercially available antimicrobial solutions such as $0.2 \%$ Chlorhexidine, 2\% Triclosan, 1\% Sodium hypochlorite, $3 \%$ Hydrogen peroxide, Dettolin, etc, some home-made microbial solutions like 3\% neem, salt water may be recommended for preservation of toothbrushes. Their efficacy in tooth brush sanitation may be compared with physical methods in future research.

\section{CONCLUSION}

The tooth brushes preserved in unsanitary conditions are a potential source of contamination that can predispose to oral and general diseases especially among immunocompromized individuals. Rinsing the tooth brush with $0.2 \%$ chlorhexidine substantially reduced the microbial contamination in all the three settings. Dipping the tooth brushes in any antimicrobial solutions may be considered as an option to reduce microbial contamination. Besides, homecare procedures such as air drying, dipping the tooth brush in salt water and use of portable sanitizers 
may be advised by dentists as part of routine oral hygiene instructions.

\section{ACKNOWLEDGEMENTS}

The investigators sincerely thank all the participants for their kind cooperation and participation.

\section{ABBREVIATION}

CFU:

ADA:

TSB:

CONSORT: Consolidated Standards of Reporting Trials

\section{Highlights of Paper}

- The article assessed the microbial contamination of tooth brushes preserved in three different sanitary settings before and after disinfection with $0.2 \%$ chlorhexidine.

- The microbiological assay of tooth brush samples collected from three different settings before intervention demonstrated the difference in the microbial contamination occurring in different settings.

- The post disinfection microbial assay demonstrated the disinfecting efficacy of $0.2 \%$ chlorhexidine in reducing such contamination.

\section{Author Profile}

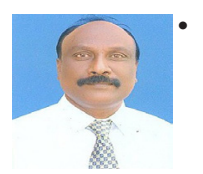

- Dr. Jagadeeshwar Rao Sukhabogi: Is presently working as Associate Professor, Department of Public Health Dentistry, Govt Dental College and Hospital, Hyderabad, Telangana State, India.

\section{REFERENCES}

1. Carranza FA, Newman MG. A textbook of Clinical Periodontology. $8^{\text {th }}$ ed. Philadelphia: WB. Saunders; 1996. pp. 493.

2. Karibasappa GN, Nagesh L, Sujatha BK. Assessment of microbial contamination of toothbrush head: An in vitro study. Indian J Dent Res. 2011; 22(1): 2-5.

3. Wetzel WE, Schaumburg C, Ansari F, Kroeger T, Sziegoleit A. Microbial contamination of toothbrushes with different principles of filament anchoring. J Am Dent Assoc. 2005; 136(6): 758-64.

4. Taji SS, Rogers AH. The microbial contamination of toothbrush: A pilot study. Aust Dent J. 1998; 43(2): 128-30.

5. Fernandez $\mathrm{V}$, Cesar D. Microbiology evaluation of toothbrushes. In vitro Cell Dev Biol Anim. 2006; 42(1): 31A.

6. Boylan R, Li Y, Simeonova L, Sherwin G, Kreismann J, Craig RG, et al. Reduction in bacterial contamination of toothbrushes using violight, ultraviolet light activated toothbrush sanitizer. Am J Dent. 2008; 21(5): 313-17.

7. Yankell SL, Saxer UP. Toothbrushes and Tooth brushing methods. In: Harris NO, Garcia-Godoy F. Primary Preventive Dentistry. $6^{\text {th }}$ ed. New Jersy: Prentice Hall; 2004. p.110.

8. Glaze PM, Wade AB. Tooth brush age and wear as it relates to plaque control. J Clin Periodontol. 1986; 13(1): 52-6.

9. Sumasogi HP, Subbareddy VV, ShashiKiran ND. Contamination of tooth brush at different time intervals and effectiveness of various disinfecting solutions in reducing the contamination of tooth brush. J Indian Soc Prev Dent. 2002; 20(3): 81-5.

10. Chandra Shekar, Nagarajappa R, Singh R, Thakur R. Antimicrobial efficacy of Acacia nilotica, Murraya koenigii L. Sprengel, Eucalyptus hybrid, and Psidium guajava on primary plaque colonizers: An in vitro comparison between hot and cold extraction process. J Indian Soc Periodontol. 2015; 19(2): 174-9.

11. Shivakumar KM, Vidya SK, Chandu GN. Dental Caries Vaccine. Indian J Dent Res. 2009; 20(1): 99-106.

12. Chandra Shekar BR, Nagarajappa R, Singh R, Thakur R. An in vitro study on the antimicrobial efficacy of ten herbal extracts on primary plaque colonizers. J Young Pharm. 2014; 6(4): 33-9.

13. Brandt ME. Candida and Candidiasis. Emerg Infect Dis. 2002; 8(8): 876.

14. Abd-ulnabi RM. Bacterial contamination of tooth brushes with comparison of healthy and dental patients. Basrah Journal of Science 2012; 30(1): 120-30.

15. Long SR, Santos AS, Nascimento CM. Avaliaçao da contaminaçao deescovas dentais por enterobactérias. Rev Odontol Univ Santo Amaro 2000; 5(1): 21-5.

16. Balappanavar AY, Nagesh L, Ankola AV. Antimicrobial efficacy of various disinfection solutions in reducing the contamination of tooth brushes. Oral Health Prev Dent. 2009; 7(2): 137-45. 